$06.4 ; 06.5$

\title{
Получение высокодисперсного порошка монооксида олова методом испарения-конденсации при нагреве сфокусированным излучением субтерагерцевого гиротрона
}

\author{
(C) А.И. Цветков ${ }^{1,2}$, А.В. Водопьянов ${ }^{1,3}$, Д.А. Мансфельд ${ }^{1}$, А.А. Орловский ${ }^{1}$, С.А. Буланова ${ }^{1,3}$, \\ Н.В. Алексеев ${ }^{1,4}$, М.А. Синайский ${ }^{1,4}$, А.В. Самохин ${ }^{1,4}$ \\ ${ }^{1}$ Институт прикладной фризики РАН, Нижний Новгород, Россия \\ ${ }^{2}$ Волжский государственный университет водного транспорта, Нижний Новгород, Россия \\ ${ }^{3}$ Нижегородский государственный университет им. Н.И. Лобачевского, Нижний Новгород, Россия \\ ${ }^{4}$ Институт металлургии и материаловедения им. А.А. Байкова РАН, Москва, Россия \\ E-mail: tsvetkov@ipfran.ru
}

Поступило в Редакцию 10 сентября 2020 г.

В окончательной редакции 30 ноября 2020 г.

Принято к публикации 30 ноября 2020 г.

Исследован способ получения высокодисперсного порошка монооксида олова $(\mathrm{SnO})$ методом испаренияконденсации при нагреве исходного материала сфокусированным излучением субтерагерцевого гиротрона с частотой $0.26 \mathrm{THz}$ и мощностью $1 \mathrm{~kW}$. Процесс проводился при продувке азотом, инертным по отношению к $\mathrm{SnO}$. Получен порошок с весовым содержанием $\mathrm{SnO}$, равным 92\%. Площадь удельной поверхности составила $7.20 \mathrm{~m}^{2} / \mathrm{g}$, что соответствует среднему размеру частиц $130 \mathrm{~nm}$. Проанализированы характеристики полученного порошка. Продемонстрирована применимость экспериментальной установки для получения высокодисперсных порошков из соединений, требующих специальных газовых условий в процессе испаренияконденсации.

Ключевые слова: гиротрон, оксид олова (II), высокодисперсный порошок, испарение-конденсация.

DOI: 10.21883/PJTF.2021.05.50680.18544

В настоящее время высокодисперсные порошки простых неорганических веществ и их соединений представляют большой интерес для целого ряда приложений: создание новых материалов и покрытий с уникальными свойствами, направленный транспорт лекарственных веществ, создание катализаторов химических реакций и т. д. $[1,2]$.

Существует ряд способов получения различных высокодисперсных порошков, среди которых одним из самых распространенных является метод испаренияконденсации [3-5], хорошо подходящий для получения наноразмерных порошков различных металлов и оксидов. Так, в работе [6] для нагрева и испарения исходного вещества было предложено использовать непрерывное излучение гиротрона с частотой $24 \mathrm{GHz}$ и максимальной мощностью излучения до $7 \mathrm{~kW}$, что позволило достичь интенсивности излучения на поверхности образца более $10 \mathrm{~kW} / \mathrm{cm}^{2}$. Дальнейшее развитие предложенный подход получил в работе [7], где для нагрева применялась установка на основе гиротрона с частотой $0.26 \mathrm{THz}$ и максимальной выходной мощностью $1 \mathrm{~kW}$, которая при необходимости позволяет добиться интенсивности излучения на поверхности испаряемого материала до $20 \mathrm{~kW} / \mathrm{cm}^{2}$. В описанных работах $[6,7]$ рассмотрены экспериментальные исследования получения нанопорошков оксидов $\mathrm{WO}_{3}, \mathrm{ZnO}$ и $\mathrm{SnO}_{2}$. Целью настоящей работы является исследование возможности получения высокодисперсного порошка монооксида олова $(\mathrm{SnO})$ методом испарения-конденсации при нагреве исходного материала излучением субтерагерцевого гиротрона. Оксид олова (II) может быть использован, например, в литий-ионных аккумуляторах [8]. Внедрение наноматериалов в источники энергии для их миниатюризации и улучшения характеристик является одной из перспективных возможностей применения таких материалов.

В эксперименте в качестве исходного материала использовался свободно насыпанный порошок монооксида олова $(\mathrm{SnO})$ с размером частиц в диапазоне 5-10 $\mu \mathrm{m}$. Нагрев материала проводился на установке, подробно описанной в [7]. Непрерывное излучение гиротрона с частотой $0.26 \mathrm{THz}$ и мощностью $1 \mathrm{~kW}$ аналогично экспериментам в работе [9] направлялось с помощью фокусирующего зеркала на поверхность исходного вещества через кварцевое окно толщиной $5 \mathrm{~mm}$, после чего за счет микроволнового нагрева происходило испарение вещества. Схема эксперимента представлена на рис. 1, a. Через отверстие, перпендикулярное поверхности образца, подавался поток закалочного газа (азота), который смешивался с парами материала, что приводило к их быстрому охлаждению и конденсации. Полученные частицы осаждались на водоохлаждаемые стенки камеры, затем осуществлялся сбор частиц для последующего анализа. Диаметр фокальной перетяжки микроволнового пучка гиротрона составляет около $2.5 \mathrm{~mm}$, что соответствует интенсивности излучения в ней около $20 \mathrm{~kW} / \mathrm{cm}^{2}$ при номинальной мощности гиротрона $1 \mathrm{~kW}$. Однако 


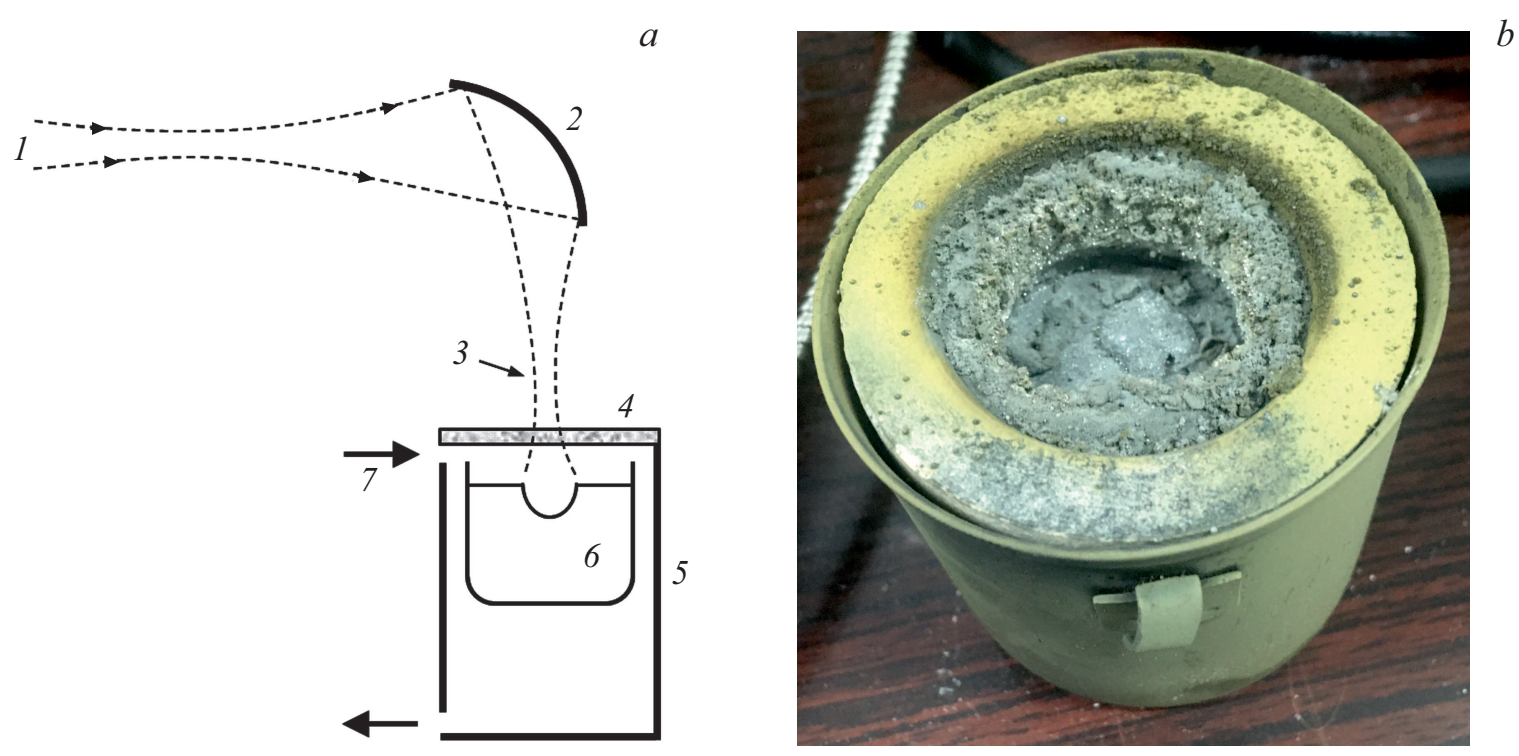

Рис. 1. Схема эксперимента $(a)$ и тигель с порошком $\mathrm{SnO}$ после процесса испарения (диаметр внешнего тигля из нержавеющей стали составляет $55 \mathrm{~mm})(b) .1$ - излучение гиротрона, 2 - фокусирующее зеркало, 3 - фокальная перетяжка пучка излучения гиротрона, 4 - кварцевое стекло, 5 - камера с водоохлаждаемыми стенками, 6 - тигель с испаряемым материалом, 7 - поток закалочного газа (азота).

в экспериментах с фокусировкой непосредственно на поверхности материала быстро образовывался слишком глубокий кратер, в результате чего резко изменялся поток закалочного газа и уменьшался выход конечного продукта. Поэтому тигель с исходным материалом был сдвинут немного ниже фокальной перетяжки пучка, расстояние до которой выбиралось экспериментальным путем с целью максимизации выхода вещества. Для компенсации возможного недостатка интенсивности излучения в области расплава за счет дополнительной теплоизоляции исходный материал помещался в керамический тигель, который в свою очередь устанавливался в тигель из нержавеющей стали. Фотография тиглей после процесса испарения представлена на рис. $1, b$.

В наших экспериментах в качестве закалочного газа применялся азот по следующим соображениям. При нагревании оксид олова (II) разлагается при температуре выше $400^{\circ} \mathrm{C}$ с образованием оксида олова (IV) и металлического олова: $2 \mathrm{SnO} \rightarrow \mathrm{SnO}_{2}+\mathrm{Sn}$. При этом нагрев свыше $1000^{\circ} \mathrm{C}$ приводит к смещению равновесия реакции в сторону образования исходного монооксида олова. Данный процесс может не произойти, если в системе присутствует кислород. Оксид олова (II) окисляется кислородом воздуха при нагревании выше $220^{\circ} \mathrm{C}$, что приводит к образованию оксида олова (IV): $2 \mathrm{SnO}+\mathrm{O}_{2} \rightarrow 2 \mathrm{SnO}_{2}$; аналогично ведет себя и олово при нагреве выше $200^{\circ} \mathrm{C}: \mathrm{Sn}+\mathrm{O}_{2} \rightarrow \mathrm{SnO}_{2}$ [10]. В связи с этим проведение процесса при продувке азотом (инертным по отношению к монооксиду олова) было необходимо, чтобы предотвратить побочные реакции окисления. Для генерации азота использовался криогенный газификатор DPL450-175-2.3I (Zhangjiagang CIMC
Sanctum Cryogenic Equipment Co., Ltd., Китай). Скорость потока закалочного газа подбиралась так, чтобы обеспечить эффективное протекание процесса с точки зрения скорости и количества наработки порошка.

Площадь удельной поверхности $S$ порошка измерялась методом БЭТ (Брунауэра-Эммета-Теллера) на анализаторе удельной поверхности TriStar 3000 (Micromeritics) и составила $7.20 \pm 0.04 \mathrm{~m}^{2} / \mathrm{g}$, что соответствует среднему диаметру частицы $D=130 \mathrm{~nm}$. Значение $D$ определялось исходя из измеренного значения удельной поверхности по формуле $D=6 /(S \rho)$, где $\rho=6.45 \mathrm{~g} / \mathrm{cm}^{3}$ - плотность монооксида олова. В эксперименте расход закалочного газа (азота) равнялся $4.4 \mathrm{~m}^{3} / \mathrm{h}$, а средняя скорость наработки вещества составила около $55 \mathrm{~g} / \mathrm{h}$.

Рентгенофазовый анализ полученного порошка проводился на порошковом рентгеновском дифрактометре X'pertPro (MPD, PANanalytical) с использованием базы данных ICSD и программного пакета X'pert в монохроматизированном медном излучении при комнатной температуре. Согласно результатам, полученным с использованием количественного программного анализа на базе метода Ритвельда, в исследуемом образце порошка относительное весовое содержание фаз следующее: $\mathrm{SnO}-92 \%, \mathrm{Sn}-5 \%, \mathrm{SnO}_{2}-3 \%$, все представленные фазы имеют тетрагональную решетку. Рентгенограмма порошка с расшифровкой фаз приведена на рис. 2, $a$.

Анализ морфологии и характерного размера частиц проводился на растровом электронном микроскопе (PЭМ) Scios (FEI). В исследуемом порошке (рис. 3) обнаружены частицы округлой/сферической формы, а 

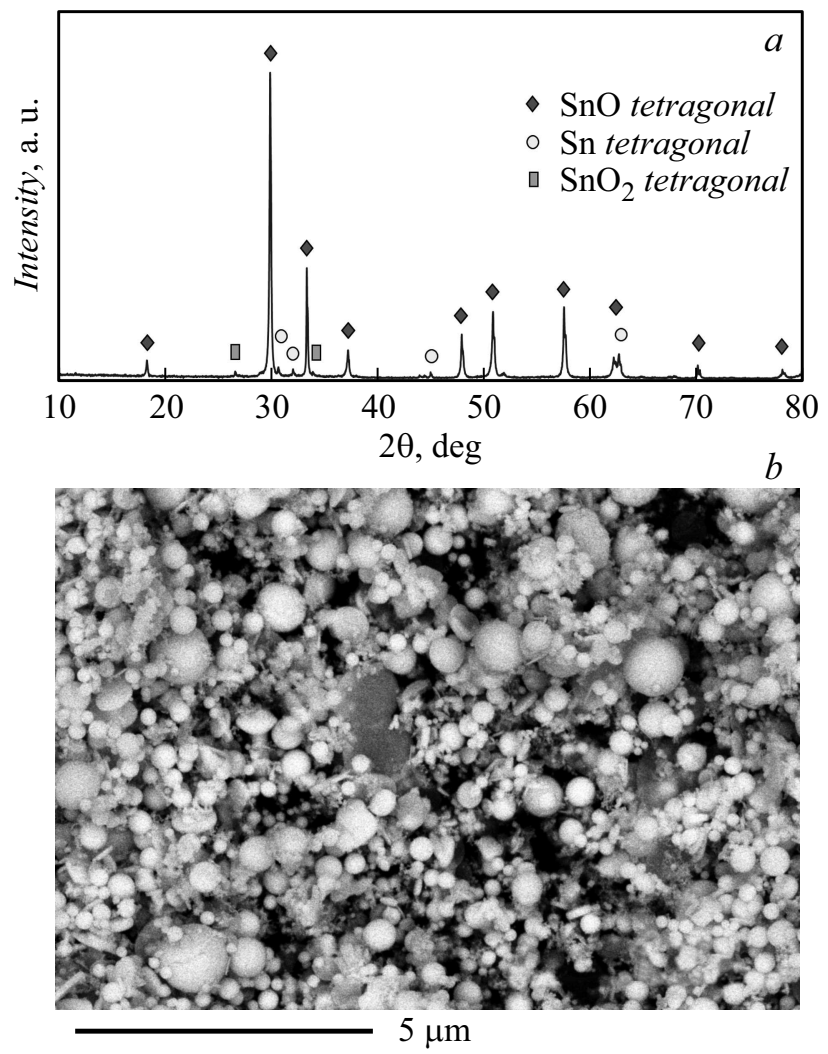

Рис. 2. Анализ полученного высокодисперсного порошка. $a$ - рентгенограмма полученного порошка оксида олова, $b$ - РЭМ-фотография полученного порошка $\mathrm{SnO}$ в режиме комбинированного детектора, захватывающего отраженные и вторичные электроны.

также частицы в форме диска с размерами от $10 \mathrm{~nm}$ до $1 \mu \mathrm{m}$.

Образец многофазной композиции был исследован на РЭМ в режиме комбинированного детектора, захватывающего обратно отраженные и вторичные электроны, что позволяет характеризовать атомный контраст материалов (чем светлее оттенок, тем тяжелее элемент). На РЭМ-фотографии (рис. 2, $b$ ) видны частицы и их области различных оттенков, характеризующих присутствие разных элементов и соединений в порошках. Для исследуемой композиции разные оттенки могут быть обусловлены частицами с различным содержанием кислорода: в ряду $\mathrm{Sn} \rightarrow \mathrm{SnO} \rightarrow \mathrm{SnO}_{2}$ оттенки отображения материалов на РЭМ-фотографии будут меняться от светлого к темному. Видно, что ярких областей $(\mathrm{Sn})$, как и темных $\left(\mathrm{SnO}_{2}\right)$, не так много. Основной объем порошка составляют частицы одного оттенка $(\mathrm{SnO})$.

Измерение гранулометрического состава порошка проводилось на анализаторе размера частиц методом лазерной дифракции Mastersizer 2000М с помощью автоматического модуля диспергирования и подачи образцов Hydro 2000S (Malvern).

Результаты гранулометрического анализа порошка $\mathrm{SnO}$ показывают, что образец имеет тримодальное объемное распределение частиц по размерам (рис. 3,a) с присутствием основной моды в диапазоне $0.5-4 \mu \mathrm{m}$ с пиком около $1.5 \mu \mathrm{m}$ и дополнительных мод мелких частиц в диапазоне $0.04-0.5 \mu \mathrm{m}$ с пиком около $0.2 \mu \mathrm{m}$ и крупных частиц (и/или агломератов из частиц) в диапазоне 4-25 $\mu \mathrm{m}$ без характерного пика. Многомодальность распределения частиц по размерам, как правило, характеризует полидисперсные порошки, полученные в неравновесных условиях газофазных процессов. Кроме того, частицы нанопорошков всегда склонны к образованию агломератов и агрегатов, что может объяснять образование различных мод, установленное по результатам гранулометрического анализа.

Полученный порошок имеет одномодальное счетное (количественное) распределение частиц по размерам (рис. 3,b) с присутствием одной моды в диапазоне $0.02-0.5 \mu \mathrm{m}$ с пиком около $0.06 \mu \mathrm{m}$. Такое распределение (с характером, близким к логарифмически нормальному) характеризует порошки, полученные в результате газофазного процесса с преимущественно коагуляционным механизмом формирования частиц.

Исследована возможность получения высокодисперсных порошков оксида олова $\mathrm{SnO}$ методом испаренияконденсации из исходного свободно насыпанного крупнодисперсного порошка (со средним размером частиц около 5-10 $\mu \mathrm{m})$ при нагреве сфокусированным излучением субтерагерцевого гиротрона. В полученном порошке содержались следующие фазы: $\mathrm{SnO}$ - 92\%, $\mathrm{Sn}-5 \%, \mathrm{SnO}_{2}-3 \%$ (весовое содержание). Площадь удельной поверхности составила $7.20 \mathrm{~m}^{2} / \mathrm{g}$, что соответствует среднему размеру частиц $130 \mathrm{~nm}$. Продемонстрирована применимость экспериментальной установки для получения высокодисперсных порошков соединений,
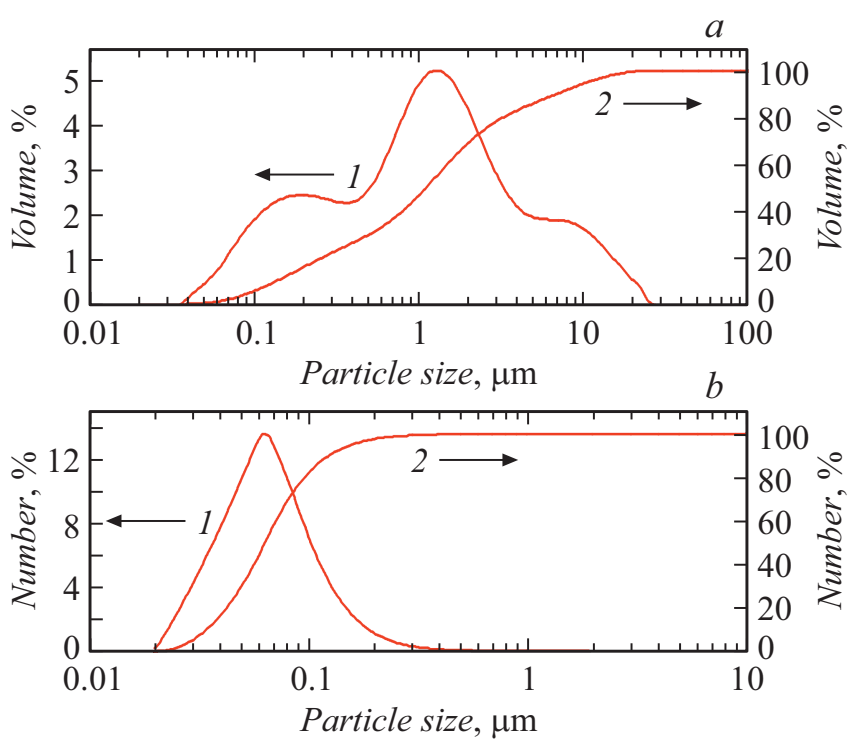

Рис. 3. Распределения частиц полученного порошка $\mathrm{SnO}$ по размерам: $a$ - объемное, $b-$ счетное (количественное). 1 дифференциальная функция распределения, 2 - интегральная функция распределения. 
требующих специальных газовых условий в процессе испарения-конденсации.

\section{Финансирование работы}

Работа выполнена при поддержке Российского научного фонда (проект № 18-79-10194).

\section{Конфликт интересов}

Авторы заявляют, что у них нет конфликта интересов.

\section{Список литературы}

[1] M.T. Swihart, Curr. Opin. Colloid Interface Sci., 8 (1), 127 (2003). DOI: 10.1016/S1359-0294(03)00007-4

[2] C. Granqvist, L. Kish, W. Marlow, Gas phase nanoparticle synthesis, 1st ed. (Springer Science \& Business Media, Berlin, 2004). DOI: 10.1007/978-1-4020-2444-3

[3] A. Lorke, M. Winterer, R. Schmechel, C. Schulz, Nanoparticles from the gasphase: formation, structure, properties (Springer, Berlin-Heidelberg, 2012). DOI: $10.1007 / 978-3-642-28546-2$

[4] R. Vajtai, Springer handbook of nanomaterials (Springer Science \& Business Media, Berlin-Heidelberg, 2013). DOI: $10.1007 / 978-3-642-20595-8$

[5] Z. Guo, L. Tan, Fundamentals and applications of nanomaterials (Artech House, Norwood, MA, 2009).

[6] A.V. Samokhin, N.V. Alexeev, A.V. Vodopyanov, D.A. Mansfeld, Y.V. Tsvetkov, J. Nanotechnol. Eng. Med., 6 (1), 011008 (2015). DOI: 10.1115/1.4032015

[7] A.V. Vodopyanov, A.V. Samokhin, N.V. Alexeev, M.A. Sinayskiy, A.I. Tsvetkov, M.Yu. Glyavin, A.P. Fokin, V.I. Malygin, Vacuum, 145, 340 (2017). DOI: $10.1016 /$ j.vacuum.2017.09.018

[8] C. Gervillié, A. Boisard, J. Labbé, S. Berthon-Fabry, K. Guérin, Synth. Met., 267, 116477 (2020). DOI: 10.1016/j.synthmet.2020.116477

[9] M.Y. Glyavin, A.V. Chirkov, G.G. Denisov, A.P. Fokin, V.V. Kholoptsev, A.N. Kuftin, A.G. Luchinin, G.Y. Golubyatnikov, V.I. Malygin, M.V. Morozkin, V.N. Manuilov, M.D. Proyavin, A.S. Sedov, E.V. Sokolov, E.M. Tai, A.I. Tsvetkov, V.E. Zapevalov, Rev. Sci. Instrum., 86 (5), 054705 (2015). DOI: 10.1063/1.4921322

[10] C.M. Campo, J.E. Rodríguez, A.E. Ramírez, Heliyon, 2 (5), e00112 (2016). DOI: 10.1016/j.heliyon.2016.e00112 